\title{
Analysis of Consultation Cases Referred from Pediatrics Department to Dermatology Outpatient Clinic: Retrospective Study
}

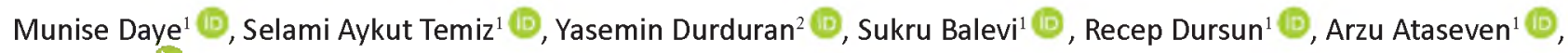 \\ Ilkay Ozer ${ }^{1}$ (D) \\ ${ }^{1}$ Necmettin Erbakan University, Meram Medical Faculty, Department of Dermatology \\ 2 Necmettin Erbakan University, Meram Medical Faculty, Department of Public Health \\ Correspondence Author: Selami Aykut Temiz \\ E-mail: aykutmd42@gmail.com \\ Received: 21.01.2019 Accepted: 01.06.2019
}

\begin{abstract}
Objective: There are a few studies in the literature about dermatology consultations requested from Pediatrics Department. In the present study, it was aimed to assess the clinical features, pre-diagnosis and dermatologic diagnosis of patients consulted to the Dermatology Department from Pediatrics Department, and also to detect possible different approaches between the clinics.

Methods: The list of dermatology consultations requested from Pediatrics Department between 1 September 2016 and 1 September 2017 were retrospectively evaluated by means of pre-diagnosis, dermatological diagnosis and unit consultations.

Results: The mean age of patients was $7.4 \pm 5.3$ years. Of the 628 patients, $52.1 \%$ were males, and $85 \%$ of the consultations were requested from outpatient clinics and $15 \%$ were from the inpatient clinics. Among all consultations $28.7 \%$ general pediatrics unit and $17.5 \%$ pediatric emergency unit required consultations. The most common diagnosis reported from Dermatology Department were eczema (28.2\%), viral diseases (13.2\%), parasitic diseases (8.4\%) and fungal diseases (5.4\%). Although, the ratio of an accurate pre-diagnosis was significantly higher in consultations requested from the inpatient clinics than those from outpatient clinics( $p<0.001), 42.7 \%$ of the patients were referred to Dermatology Outpatient Clinic with an incorrect pre-diagnosis.

Conclusion: Almost half of the patients, who were referred to Dermatology consultation, were diagnosed with incorrect pre-diagnosis. It was seen that pediatricians were difficult to recognize dermatoses. The awareness of Pediatric Dermatology Department should be raised for both specialties. Keywords: Pediatric dermatology, dermatology consultation, dermatology
\end{abstract}

\section{INTRODUCTION}

At least $30 \%$ of the patients, who are admitted to the Pediatrics Department, have dermatological complaints, and $30 \%$ of the dermatological examinations involve pediatric patients $(1,2)$. Therefore, pediatric dermatology has a significant place for both specialties. The distribution and prevalence of dermatological diseases varies between pediatric and adult patients (3). The skin involvement of syndromes, napkin (diaper) dermatitis, atopic dermatitis, viral, bacterial and fungal infections, are more common in this age group (4). Pediatric patients are primarily admitted to Pediatrics Department with skin complaints, or dermatosis are detected by a pediatrician during the follow-up or examination of another disease (5). In the epidemiological studies, the prevalence of pediatric cutaneous diseases was reported in the range of $9-37 \%(1,2)$. Therefore, it is important for pediatricians to recognize the dermatitis and to make a right referral. Skin symptoms originate from primary dermatosis and other systemic disease, as well. It has been known that specialists, except the Dermatology Department, have challenges in recognizing and commenting the skin symptoms $(6,7)$.
In the present study, it was aimed to assess the clinical features, pre-diagnosis and dermatologic diagnosis of inpatients and/or outpatients who were consulted to the Dermatology Department from Pediatrics Department.

\section{METHODS}

Present study was conducted in Necmettin Erbakan University Meram Medical Faculty. Dermatology consultation cases requested from Pediatrics Departments between 1 September 2016 and 1 September 2017 were retrospectively evaluated. The clinic asking for the consultation, reasons for consultation, the anamnesis, examination findings, pre-diagnosis for the consultation of the physician, and the symptoms and examination findings diagnosed in the Dermatology Department, diagnostic procedures in the Dermatology Department, recommended therapies, and applied treatments were recorded by searching the hospital automation system and patient files. The patients were evaluated by the same dermatologist and consulted with the senior ones in case of a need. The study was approved by Local ethics committee of Necmettin Erbakan University, Meram Medical Faculty (date: 2017, number: 1029). 


\subsection{Statistical Analysis}

Data analysis was performed using SPSS 22.0 program. The normal distribution suitability of the variables was tested with One sample Kolmogorov-Smirnov. Mean \pm standard deviation and percentage were used for descriptive statistics. Chi-square test was performed and the $p$ value of less than 0.05 was accepted as statistically significant.

\section{RESULTS}

A total of 628 patients, for whom the consultation of Dermatology Department was requested from the Pediatrics outpatient clinics and inpatient clinics, were included in the study. The ratios of consultations that were requested from outpatient clinics and inpatient clinics were $85 \%$ and $15 \%$, respectively. The consultations were mostly requested from the hospital units of general pediatrics $(28.7 \%)$, pediatric emergency $(17.5 \%)$, pediatric hematology $(13.2 \%)$ and pediatric allergy and immunology (10.5\%). The outpatient clinic of general pediatrics $(27.7 \%)$ and pediatric hematology clinic (4\%) were placed on the top among outpatient clinics and inpatient clinics, respectively. The distribution of clinics and the number of requested consultations were presented in Table 1.

Table 1. The number and percentage of dermatologic consultations in different pediatric clinics

\begin{tabular}{|l|c|c|c|}
\hline \multicolumn{1}{|c|}{$\begin{array}{c}\text { Unit requested } \\
\text { consultation }\end{array}$} & $\begin{array}{c}\text { Number of } \\
\text { patients } \\
\text { n (\%) }\end{array}$ & $\begin{array}{c}\text { Unit requested } \\
\text { consultation }\end{array}$ & $\begin{array}{c}\text { Number of } \\
\text { patients } \\
\text { n (\%) }\end{array}$ \\
\hline $\begin{array}{l}\text { General Pediatrics } \\
\text { OC. }\end{array}$ & $174(27.7 \%)$ & $\begin{array}{c}\text { P. Intensive Care } \\
\text { Unit }\end{array}$ & $8(1.3 \%)$ \\
\hline Pediatric Emergency & $110(17.5 \%)$ & P. Pulmonary Dis. IC. & $8(1.3 \%)$ \\
\hline $\begin{array}{l}\text { P. Allergy- } \\
\text { Immunology OC. }\end{array}$ & $62(9.9 \%)$ & $\begin{array}{c}\text { General Pediatrics } \\
\text { IC. }\end{array}$ & $8(1.3 \%)$ \\
\hline P. Hematology OC. & $58(9.2 \%)$ & P. Nephrology IC. & $6(1 \%)$ \\
\hline P. Endocrinology OC. & $46(7 . \% 3)$ & P. Neurology IC. & $6(1 \%)$ \\
\hline P. Hematology IC. & $25(4 \%)$ & P. Surgery IC. & $5(0.8 \%)$ \\
\hline P. Nephrology OC. & $18(2.9 \%)$ & P. Surgery OC. & $5(0.8 \%)$ \\
\hline P. Pulmonary Dis. OC. & $17(2.7 \%)$ & P. Oncology OC. & $5(0.8 \%)$ \\
\hline P. Neurology OC. & $16(2.5 \%)$ & P. Oncology IC. & $4(0.6 \%)$ \\
\hline P. Infectious Dis. OC. & $14(2.5 \%)$ & P. Cardiology IC. & $3(0.5 \%)$ \\
\hline P. Endocrinology IC. & $9(1.4 \%)$ & P. Infectious Dis. IC. & $3(0.5 \%)$ \\
\hline Newborn IC. & $8(1.3 \%)$ & $\begin{array}{c}\text { P. Gastroenterology } \\
\text { IC. }\end{array}$ & $2(0.3 \%)$ \\
\hline $\begin{array}{l}\text { P. Gastroenterology } \\
\text { OC. }\end{array}$ & $8(1.3 \%)$ & & \\
\hline P. Pediotrics, DIs. Diseas & & \\
\hline
\end{tabular}

P.: Pediatrics, Dis.: Diseases, OC.: Outpatient clinic, IC.: Inpatient clinic, n: number

Of the patients, $42 \%$ had a comorbid disease. These comorbidities were acute lymphocytic leukemia (ALL) in 55 patients $(8.8 \%)$, immune deficiency in 23 patients $(3.7 \%)$, Type-1 Diabetes Mellitus in 14 patients (2.3\%) and epilepsy in 12 patients (1.9\%), respectively. The ratio of consultations requested from the inpatient clinics were higher than those from outpatient clinics and emergency department in case of a comorbid disease $(p<0.001)$. The ratio of correct pre-diagnosis was higher in consultations requested from inpatient clinics than those from outpatient clinics $(p<0.001)$.
Table 2. Dermatological diagnoses made by pediatric departments and dermatologists

\begin{tabular}{|c|c|c|c|}
\hline Pre-diagnosis & $\begin{array}{l}\text { Patient } \\
\mathrm{n}(\%)\end{array}$ & $\begin{array}{c}\text { Final dermatological } \\
\text { diagnoses }\end{array}$ & $\begin{array}{l}\text { Patient } \\
\mathrm{n}(\%)\end{array}$ \\
\hline Eczema & $197(31.4 \%)$ & Eczema & $\begin{array}{c}177 \\
(28.2 \%)\end{array}$ \\
\hline Atopic dermatitis & $71(11.3 \%)$ & Atopic dermatitis & $49(7.8 \%)$ \\
\hline Irritant contact dermatitis & $59(9.4 \%)$ & $\begin{array}{c}\text { Irritant contact } \\
\text { dermatitis }\end{array}$ & $40(6.4 \%)$ \\
\hline Diaper dermatitis & $26(4.1 \%)$ & Diaper dermatitis & $19(3 \%)$ \\
\hline \begin{tabular}{|l|} 
Allergic contact \\
dermatitis \\
\end{tabular} & $23(3.7 \%)$ & Seborrheic dermatitis & $16(2.5 \%)$ \\
\hline Seborrheic dermatitis & $15(2.4 \%)$ & $\begin{array}{c}\text { Allergic contact } \\
\text { dermatitis }\end{array}$ & $14(2.2 \%)$ \\
\hline Nummular dermatitis & $2(0.3 \%)$ & Nummular dermatitis & $14(2.2 \%)$ \\
\hline \multirow[t]{2}{*}{\begin{tabular}{|l} 
Pityriasis alba \\
\end{tabular}} & $1(0.2 \%)$ & Pityriasis alba & $14(2.2 \%)$ \\
\hline & & Neurodermatitis & $11(1.8 \%)$ \\
\hline Viral Diseases & $74(11.7 \%)$ & Viral Diseases & $\begin{array}{c}83 \\
(13.2 \%) \\
\end{array}$ \\
\hline Verruca Vulgaris & $18(2.9 \%)$ & Verruca Vulgaris & $18(2.9 \%)$ \\
\hline Primary herpes infection & $15(2.4 \%)$ & $\begin{array}{c}\text { Primary herpes } \\
\text { infection }\end{array}$ & $17(2.7 \%)$ \\
\hline Zona zoster & $15(2.4 \%)$ & $\begin{array}{c}\text { Viral exanthema } \\
\text { disease }\end{array}$ & $17(2.7 \%)$ \\
\hline Viral exanthema disease & $14(2.2 \%)$ & Zona zoster & $16(2.5 \%)$ \\
\hline Varicella zoster & $11(1.8 \%)$ & Varicella zoster & $12(1.9 \%)$ \\
\hline Molluscum contagiosum & $1(0.2 \%)$ & $\begin{array}{c}\text { Molluscum } \\
\text { contagiosum }\end{array}$ & $3(0.5 \%)$ \\
\hline Fungal Diseases & $55(8.7 \%)$ & Fungal Diseases & $34(5.4 \%)$ \\
\hline Tinea corporis & $21(3.3 \%)$ & Intertriginous candida & $17(2.7 \%)$ \\
\hline Onvchomvcosis & $15(2.4 \%)$ & Tinea versicolor & $8(1.3 \%)$ \\
\hline Intertriginous candida & $10(1.6 \%)$ & Tinea corporis & $5(0.8 \%)$ \\
\hline Tinea capitis & $7(1.1 \%)$ & Tinea capitis & $4(0.6 \%)$ \\
\hline Tinea versicolor & $2(0.3 \%)$ & & \\
\hline Drug Reactions & $36(5.7 \%)$ & Drug Reactions & $31(4.9 \%)$ \\
\hline Parasitic Diseases & $31(4.9 \%)$ & Parasitic Diseases & $53(8.4 \%)$ \\
\hline Insect bites & $18(2.9 \%)$ & Insect bites & $43(6.8 \%)$ \\
\hline Pediculosis & $8(1.3 \%)$ & Scabies & $7(1.1 \%)$ \\
\hline Scabies & $5(0.8 \%)$ & Pediculosis & $3(0.5 \%)$ \\
\hline \begin{tabular}{|l|} 
Urticaria \\
\end{tabular} & $28(4.5 \%)$ & Urticaria & $33(5.3 \%)$ \\
\hline Bacterial Diseases & $28(4.5 \%)$ & Bacterial Diseases & $32(5.1 \%)$ \\
\hline Acneiform Diseases & $16(2.5 \%)$ & Acneiform Diseases & $23(3.7 \%)$ \\
\hline \begin{tabular}{|l} 
Papulosquamous \\
Diseases
\end{tabular} & $3(0.5 \%)$ & $\begin{array}{c}\text { Papulosquamous } \\
\text { Diseases }\end{array}$ & $24(3.8 \%)$ \\
\hline Psoriasis vulgaris & $2(0.3 \%)$ & Psoriasis vulgaris & $9(1.4 \%)$ \\
\hline Ichthyosis vulgaris & $1(0.2 \%)$ & Pityriasis rubra pilaris & $8(1.3 \%)$ \\
\hline & & Ichthyosis Vulgaris & $4(0.7 \%)$ \\
\hline & & Lichen planus & $3(0.5 \%)$ \\
\hline Ulcers & $2(0.3 \%)$ & Ulcers & $3(0.5 \%)$ \\
\hline $\begin{array}{l}\text { Other: (Erythema nodo- } \\
\text { sum, epidermolysis bul- } \\
\text { losa, unguis incarnatus, } \\
\text { neonatal pustulosis, ash } \\
\text { leaf, infantile hemorrha- } \\
\text { gic edema, terra firma } \\
\text { forme dermatosis, photo- } \\
\text { contact dermatitis, nons- } \\
\text { pecific) }\end{array}$ & $158(25.2 \%)$ & $\begin{array}{l}\text { Other: (Erythema no- } \\
\text { dosum, epidermolysis } \\
\text { bullosa, unguis incar- } \\
\text { natus, neonatal pus- } \\
\text { tulosis, ash leaf, in- } \\
\text { fantile hemorrhagic } \\
\text { edema, photocontact } \\
\text { dermatitis, juvenile } \\
\text { spring hemangioma, } \\
\text { miliaria, pruritus simp- } \\
\text { lex, terra firma forme, } \\
\text { nonspecific) }\end{array}$ & $\begin{array}{c}135 \\
(21.5 \%)\end{array}$ \\
\hline
\end{tabular}

n: number 
Although the patients, for whom the consultation was requested, were referred with the pre-diagnosis of eczema $(n=197 ; 31.4 \%)$, viral diseases ( $n=74 ; 11.7 \%)$, fungal infections $(n=55 ; 8.7 \%)$, patients were diagnosed with eczema ( $n=177$; $28.2 \%)$, viral diseases $(n=83 ; 13.2 \%)$, parasitic diseases $(n=53$; $8.4 \%$ ) in the dermatology department, respectively. The ratio of skin infections was detected as $32.1 \%$ (parasitic, fungal, viral and bacterial). The pre-diagnosis of Pediatrics Department requested consultation and dermatologic diagnostic groups were presented in Table 2. Elementary lesions were defined only in 113 patients (18\%) while requesting consultation, and of those, elementary lesion was incorrectly defined in 54 patients (47.8\%).

The consistency rate between the diagnosis of Pediatrics Department and Dermatology Outpatient Clinic was $57.3 \%$. In the comparison performed by considering that dermatologic

diagnosis represented the correct results, $42.7 \%$ of all patients were referred to the Dermatology Outpatient Clinic with an incorrect diagnosis. The units requested consultation with maximum incorrect diagnosis were Pediatrics Immunology Outpatient Clinic (62.9\%), General Pediatrics Outpatient Clinic (46\%) and Pediatrics Emergency Unit (44.5), respectively, and the units requested consultation with minimum incorrect diagnosis were Pediatrics Infection inpatient clinic (7.1\%), Neonatal inpatient clinic (12.5\%) and Pediatrics Pulmonary inpatient clinic (16.7\%), respectively. In patients for whom the consultation was requested, the treatment administered in their units was the wrong choice of potent topical steroid in 34 patients $(5.4 \%)$ and the use of wrong steroid for the indication in 28 patients (4.4\%) (e.g. bullous impetigo, etc.). Inappropriate emollient was given to the 48 patients (7.7\%). Dermatologic therapy had been initiated in 286 patients before referring to the Dermatology Department, and improper treatment was detected in 110 patients (38.5\%).

The first three procedures for the diagnosis were native in 115 patients (18.3\%), wood lamb in 57 patients $(9.1 \%)$ and dermatoscopy in 27 patients (4.3\%). According to the results of consultations, 31 patients received only systemic therapy (4.9\%), 232 patients received only topical therapy (36.9\%), 347 patients received systemic therapy (55.3\%), 551 patients received only topical therapy or both topical and systemic therapy $(87.7 \%)$. There were 46 patients not receiving any therapy $(7.3 \%)$. The most common treatment options were emollients and antihistamines in topical therapy and systemic therapy, respectively.

\section{DISCUSSION}

The aim of the dermatology consultation must be to define skin diseases and to differentiate the skin symptoms for the diagnosis of a systemic disease, as well. In a study investigating dermatology consultations requested from various clinics demonstrated that the consultations were frequently requested from internal diseases, pediatrics and adult emergency outpatient clinics, and $21.2 \%$ of the dermatology consultations were the consultations requested from pediatrics and pediatrics emergency outpatient clinics (7). Pediatric cases constitute about 11 to $33 \%$ of all dermatology consultations in the literature $(8,9,10)$. There are a few studies investigating dermatology consultations that are requested from pediatric cases. Afsar evaluated the dermatology consultations of 539 inpatient pediatric cases and outpatient cases were not included in the study (11). In the present study, we had assessed the dermatology consultations of 628 outpatient and inpatient pediatric patients for a year, and the number of patients was higher than the current studies in the literature. The number of consultations requested from the pediatrics outpatient clinic was highest in our study group. Similar to the other studies in the literature, the most frequent consultation requesting department of our study was general pediatrics $(4,5,11)$.

Almost half of our patients had a comorbid disease; respectively, ALL, immune deficiency and diabetes. In the study of Afsar, pediatrics inpatient consultations were evaluated, and the most common comorbidity was stated as ALL with the ratio of $4.1 \%(11)$. In the present study, the ratio of ALL detected as $8.8 \%$, which was twice higher than the ratio of Afsar study had, and dermatological problems were considered to be a common problem during the outpatient management of ALL patients. The ratio of consultations requested from inpatient clinics was higher in patient with comorbidity; and the ratio of correct pre-diagnosis received from the inpatient clinics was also higher than the others.

In our study, the most common diagnosis was atopic dermatitis in 49 patients (7.8\%). This ratio was reported as $6 \%$ and $7.7 \%$ in the study of Storan et al. evaluating pediatric consultations and in the study of McMahon et al., respectively $(5,12)$, which was compatible with our study. While consultations were requested only in $18 \%$ ( $n=113$ ) of the cases referred for consultations, elementary lesions were well defined, and the elementary lesions were incorrectly defined in $47.8 \%(n=54)$ patients. It has been seen that pediatricians have difficulties in recognizing elementary skin lesions.

In the present study, the diagnostic consistency between dermatology and consultation requested from Pediatrics were compatible with the studies of Moon et al. and Auvin et al. evaluating pediatric consultations $(13,14)$. Skin biopsy was performed to the $4-12 \%$ of general dermatology consultations in the literature $(8,15)$. In the literature, the most frequent procedure was biopsy among the pediatric consultations and but it was native in our study $(11,13,16)$.

One-fourth of the cases that were sent with the pre-diagnosis of drug reactions were received from hematology clinic. This finding was correlated to the chemotherapeutics used in the pediatrics hematology. The high frequency of drug reactions associated with multi-diseases and multi-disease therapies are within the scope of expectations.

Dermatological diseases constituted 4 to $6 \%$ of cases who were admitted to the pediatrics emergency department $(17,18)$. The ratio of consultations requested from pediatrics 
emergency was one-fifth of all consultations. This ratio was detected as high in comparison to the literature (19). This high ratio was correlated to the high number of patients administered to the pediatrics emergency department and the request of dermatology consultation to accelerate triage in the emergency clinic.

Consultation was requested with an incorrect dermatologic pre-diagnosis in almost half of the cases in whom dermatology consultation was requested. When the referral with an incorrect pre-diagnosis was evaluated within the departments, pediatrics allergy-immunology outpatient clinic, general pediatrics outpatient clinic and pediatrics emergency department were the most frequent units requesting consultation with incorrect pre-diagnosis. The units of pediatrics infectious diseases, newborn and pediatrics pulmonary diseases were the units requesting consultations with minimum number of incorrect pre-diagnosis.

In the study comparing treatment compliance of pediatricians and dermatologists, Chen et al. detected that the treatment was incompatible and partially compatible in 36\% and $36 \%$ of the cases, respectively (20). Dermatologic treatment was initiated in almost one-third of our cases before requesting dermatology consultation, and wrong treatment was detected in almost half of these patients. Incorrect prediagnosis and associated wrong treatment might lead to variations in dermatosis forms, or side effects might be observed in the patients. In addition, delays might be seen during the diagnosis and treatment of the patients.

\section{CONCLUSION}

Almost half of the patients, who were referred to Dermatology consultation, were diagnosed with incorrect dermatological symptoms. Pediatricians had difficulties in recognizing the dermatoses. The awareness of Pediatric Dermatology Department should be raised for both specialties. Seminars should be conducted for pediatricians periodically. Due to the retrospective design of the study, electronic medical records might be missing.

\section{REFERENCES}

[1] Sacchidanand S, Sahana MS, Asha GS, Shilpa K. Pattern of pediatric dermatosis at a referral centre. Indian J Pediatr 2014;81(4):375-380.

[2] Thappa DM. Common skin problems in children. Indian J Pediatr 2002;69(8):701-706.

[3] Fofana $Y$, Traore B, Dicko A, Faye O, Berthe S, Cisse L, Keita A, Tall K, Kone MB, Keita S. Epidemio-clinical profile of dermatoses in children receiving dermatological consultation in the Department of Dermatology at the National Center for Disease Control in Bamako. Pan Afr Med J 2016;2:238-238.

[4] Srinivas SM, Hiremagalore R, Venkataramaiah LD, Premalatha R. Pediatric dermatology inpatient consultations: a retrospective study. Indian J Pediatr 2015;82(6):541-544.

[5] McMahon P, Goddard D, Frieden IJ. Pediatric dermatology inpatient consultations: a retrospective study of 427 cases. J Am Acad Dermatol 2013;68(6):926-931.

[6] Bauer J, Maroon M. Dermatology inpatient consultations: a retrospective study. J Am Acad Dermatol 2010;62(3):518-519.

[7] Adışen E, Ünal S, Gürer MA. Dermatology Consultations. Turkderm-Archieves of The Turkish Dermatology and Venerology 2006;40(4):126-129.

[8] Gupta S, Sandhu K, Kumar B. Evaluation of emergency dermatological consultations in a tertiary care centre in North India. J Eur Acad Dermatol Venereol 2003;17(3):303-305.

[9] Falanga V, Schachner LA, Rae V, Ceballos PI, Gonzalez A, Liang G, Banks R. Dermatologic consultations in the hospital setting. Arch Dermatol 1994;130(8):1022-1025.

[10] Penate Y, Guillermo N, Melwani P, Martel R, Borrego L. Dermatologists in hospital wards: an 8-year study of dermatology consultations. Dermatology 2009;219(3):225231.

[11] Afsar FS. Analysis of pediatric dermatology inpatient consultations in a pediatric teaching hospital. Arch Argent Pediatr 2017;115(6):377-384.

[12] Storan ER, McEvoy MT, Wetter DA, el-Azhary RA, Hand JL, Davis DM, Bridges AG, Camilleri MJ, Davis MD. Pediatric hospital dermatology: experience with inpatient and consult services at the Mayo Clinic. Pediatr Dermatol 2013;30(4):433-437.

[13] Moon AT, Castelo-Soccio L, Yan AC. Emergency department utilization of pediatric dermatology (PD) consultations. J Am Acad Dermatol 2016;74(6):1173-1177.

[14] Auvin S, Imiela A, Catteau B, Hue V, Martinot A. Pediatric skin disorders encountered in an emergency hospital facility: a prospective study. Acta Derm Venereol 2004;84(6):451-454.

[15] Yerebakan Ö, Altunay İ, Köslü A. Evaluation of the consultations requested from the dermatology clinic. The Medical Bulletin of Sisli Etfal Hospital 1995;29:47-50

[16] Hon KL, Leung TF, Wong Y, Ma KC, Fok TF. Skin diseases in Chinese children at a pediatric dermatology center. Pediatr Dermatol 2004;21(2):109-112.

[17] Köse O. Emergency in pediatric dermatology. Turkiye Klinikleri J Surg Med Sci 2006;2(3):60-64.

[18] Sarkar R, Basu S, Patwari AK, Sharma RC, Dutta AK, Sardana K. An appraisal of pediatric dermatological emergencies. Indian Pediatrics 2000;37(4):425-430.

[19] Srinivas SM, Hiremagalore R, Venkataramaiah LD, Premalatha R. Pediatric Dermatology Inpatient Consultations: A Retrospective Study. Indian J Pediatr 2015;82(6):541-544.

[20] Chen TS, Goldyne ME, Mathes EF, Frieden IJ, Gilliam AE. Pediatric teledermatology: observations based on 429 consults. J Am Acad Dermatol 2010;62(1):61-66. 